AC 2009-619: RESEARCH ENTREPRENEUR MODEL FOR MONITORING THE PROGRESS OF FACULTY RESEARCH PROGRAMS

Scott Hinton, Utah State University 


\title{
Research Entrepreneur Model for Monitoring the Progress of Faculty Research Programs
}

\begin{abstract}
This paper describes a model that visually outlines the strength and sustainability of a faculty member's research enterprise. This model can be used by individual faculty members to identify the areas that they personally need to develop and improve as they try to build a successful research program and by administrators who need to have the ability to monitor the productivity of a faculty member's research.
\end{abstract}

\section{Overvie w}

When a new faculty member is hired at a research intensive university they are told that they will be expected to create an internationally recognized research program if they expect to be awarded tenure and promotion. The questions then asked by many of these newly hired faculty members include: What does it mean to have an internationally recognized research program? How do you create an internationally recognized research program? How do you measure success? Is a successful research program based only on the publication of refereed journal papers? What about refereed conference papers? What about patents? How does grant writing fit into this process? Are collaborations, both internal and external, viewed positively or negatively?

On the other hand, the administrators are also faced with similar questions regarding the progress and performance of young faculty members. These questions include: What are the important metrics that need to be measured and tracked ${ }^{1-4}$ ? How can you measure the respect of a faculty member in their professional community? How can a faculty member's contribution be separated from a collaborative project or grant? Finally, most administrators need to understand if the faculty member is developing a sustainable research program that will not only lead to tenure and promotion but also keep them active and productive unt il they achieve the rank of full professor.

The purpose of this paper is to describe a visual mode 1 that can be used by both faculty members and administrators to provide a year-by-year understanding of the research infrastructure that has been created by the faculty member. The basic assumption of this model is that the role of a faculty member is to de velop a research program that will allow them to become an international expert in their field of research. This implies that during the pre-tenure process each faculty member needs to develop a personal research infrastructure that will be able to support the creation, development and marketing of their ide as and intellectual property. Not only do they have to create and develop new and novel ideas, they have to sell them to their peers! By the time the faculty members go up for tenure and promotion they should have made an impact in the ir professional community. It is also necessary that they have made a strong enough impression on their peers that they are viewed as one of the experts in their field of study.

The process of creating an internationally recognized research program involves converting the space and start-up money they receive when hired into a research enterprise that will: 
1) Produce the academic products and services that will lead to a strong international reputation in their field of study. These include publications in refereed journals and conference papers, scholarship opportunities through publishing text books and research monographs, patents, consulting, and participation in service for their professional societies.

2) Obtain the funding necessary to support the infrastructure for the research enterprise which includes students, equipment, professional staff, etc. This should include government, ind ustrial, and university grants and contracts. It could also include revenues received from intellectual property developed by the enterprise.

3) Train students to participate in the creation, de velop ment, and dissemination of the products and services of the research enterprise.

In order to achieve all the requirements necessary to build a successful university-based research program, the faculty member needs to look at their role as more of a research entrepreneur rather than the focused researcher that would be found in an industrial research laboratory. A successful research enterprise will require the faculty member to; 1) create the vision and direction of the research enterprise, 2) manage a large group of stude nts and professional staff, 3) bring in funding to support the enterprise, 4) produce academic products and services, and 5) market the academic products to both industry and their professional community. All of these activities are very similar to a young entrepreneur trying to start a new business, only in this case, the products are new ideas to be sold in the academic marketplace.

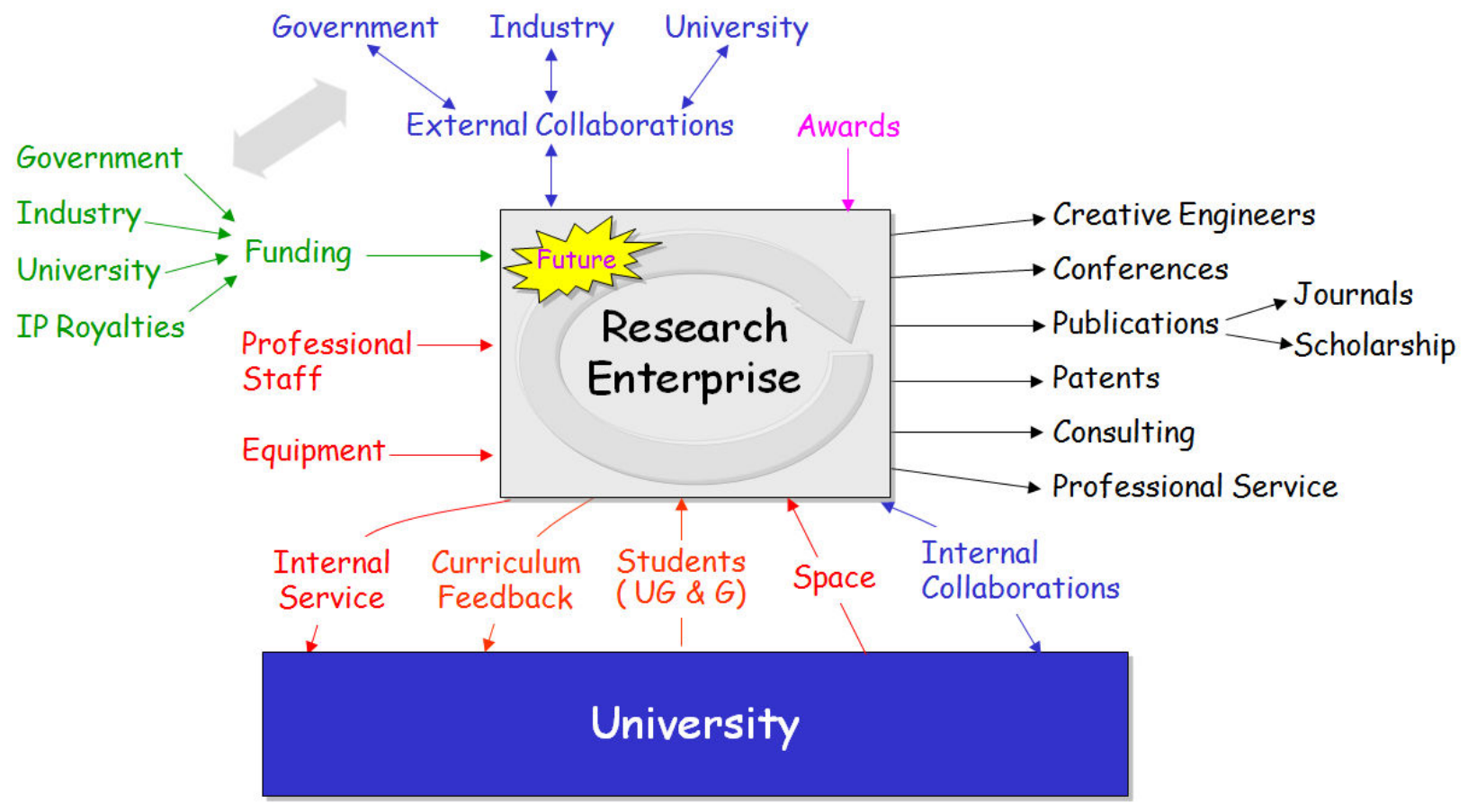

Figure 1. Research entrepreneur model 
A model that outlines some of the key measurables associated with a successful university-based research enterprise is shown in Figure 1. Each of the inputs and outputs of this model will be discussed below.

\section{Research Enterprise Products (Shown in Black)}

One of the most important concepts that new faculty members need to understand as they start to build their research enterprise is that they will be required to create and market academic products and services. Like in business, the entrepreneur is required to have some product or service to sell if they want to be successful. In academia those products and services are the publication of new ideas and intellectual property. These prod ucts and services are shown in black on the right side of the box labeled research enterprise. They are the outputs of the mode 1 ! These academic products include refereed journals, refereed conference papers, and patents. It is also important to produce scholarly works such as books, book chapters, and monographs that build on and expand the faculty member's research that has been previously published in journals and conferences. As the reputation of the research enterprise grows the faculty member will be invited to participate in services for their professional community such as journal editorships, conference chairs, and technical committees. It is important for young faculty members to understand that professional service is one of the best ways to meet and work with the leaders in their professional communities.

Consulting, another potential output of the research enterprise, is a double edged sword. The positive side of consulting provides a great opportunity to work with ind ustrial partners in creating new and exciting proprietary products based on leading-edge technologies. The negative side is that the time spent on this activity takes away from the time and effort necessary to develop the necessary international reputation for their research enterprise. If this time is used properly it can be helpful in understanding the needs of ind ustry and be a vehicle for establishing industrial collaborations. If misused, this effort can suck the life out of the research enterprise.

The final output, which involves the training of creative engineers, is the most important output of the faculty member's enterprise. Due to the time required for managing and coordinating the research enterprise, the faculty members will need to train and then trust stude nts to be their eyes and hands. A successful research enterprise will not only listen to the students ideas, but will build on them. Good students are an essential requirement of a successful research enterprise! The role of students will be discussed more below.

Now that we have described the outputs of the research enterprise, it is necessary to understand the inputs that will be required to make the research enterprise's engine work. These inputs are divided into four categories that include: building on the university's infrastructure (red), funding the research enterprise (green), extending the research enterprise (blue), and sustainability (magenta). 


\section{Building on the University's Infrastructure (Shown in Red)}

When a new faculty member is hired by a uni versity they are normally given a start-up package that includes some space to set up their research program and money for equipment, student support, travel, and, in most cases, a couple of years of summer support for them. From this start they need to develop a research enterprise that will need to grow to include more specialized equipment and e ven professional staff such as technicians and post docs that can provide support for both the faculty members and their stude nts. One of the essential keys of success is find ing and training good students, since they are the primary means to extend and develop the faculty member's ideas. A successful research enterprise will require several $\mathrm{PhD}$ students at different points in their degree. It is these senior level students that will provide training for the BS and MS students as well as supporting the work culture the faculty member is trying to create within the ir enterprise. It is also important that the faculty member is involved with their department in developing a curriculum that will provide the training their students need and also in helping though internal service activities to make the department an exciting place to be for both the stude nts and other faculty members.

\section{Funding the Research Enterprise (Shown in Green)}

In order to financially support the students and professional staff, as well as buy the equipment necessary to build a successful research enterprise, the research entrepreneur will need to find a way to fund these activities. This is a critical input to the successful operation of a research enterprise. The primary source of funding for most university-based research programs are federal grants. These are difficult to ob tain and require a large amount of effort by the faculty member. There are also other sources of funding such as industry that can be helpful but normally have conditions that do not support the goal of developing international recognition since many of the corporate contracts have serious limitations on publication and the development of intellectual property. It is important for a young faculty member to avoid the trap of becoming too dependent on restricted industrial funding.

In many institutions there are also university-based grants that can be used to add to the growth and flexibility of the enterprise. Other than the initial start-ups these grants are typically small and should not be viewed as the major means of support for the enterprise. Finally, the licensing of that intellectual property can become another source of income for the research enterprise.

\section{Extending the Research Enterprise (Shown in Blue)}

An important part of growing and extending the research enterprise into the professional community is through networking and collaboration. It is important for the faculty member to develop a network that knows the program managers of the funding agencies that support research in their areas of expertise. This network also needs to include the key technical people in the local and national industry that is based on the research area of the research enterprise. It is also important for the research entrepreneur to establish collaborative ties with government, industry, and both external and internal university researchers. A large part of the success of a research enterprise will be the success of joint proposals and publications. In today's world it is 
hard to be successful as an individual; now it is multidisciplinary teams that have been rewarded with most of the grants and other forms of funding.

\section{Sustainability (Shown in Magenta)}

An essential part of building a successful research enterprise is to always be looking into the future. As technology and funding priorities change over time a successful enterprise needs to be able to adapt. A faculty member should always be exploring new technologies and ideas to be able to adapt their expertise as the world changes, if not they will find that their funding is gone and their enterprise engine has stopped working. A good research enterprise will de vote at least $10 \%$ of its time to exploring future opportunities.

Finally, an important indicator of the faculty member's external reputation includes awards received from their professional community. These awards are perhaps the most important indicator of success and sustainability.

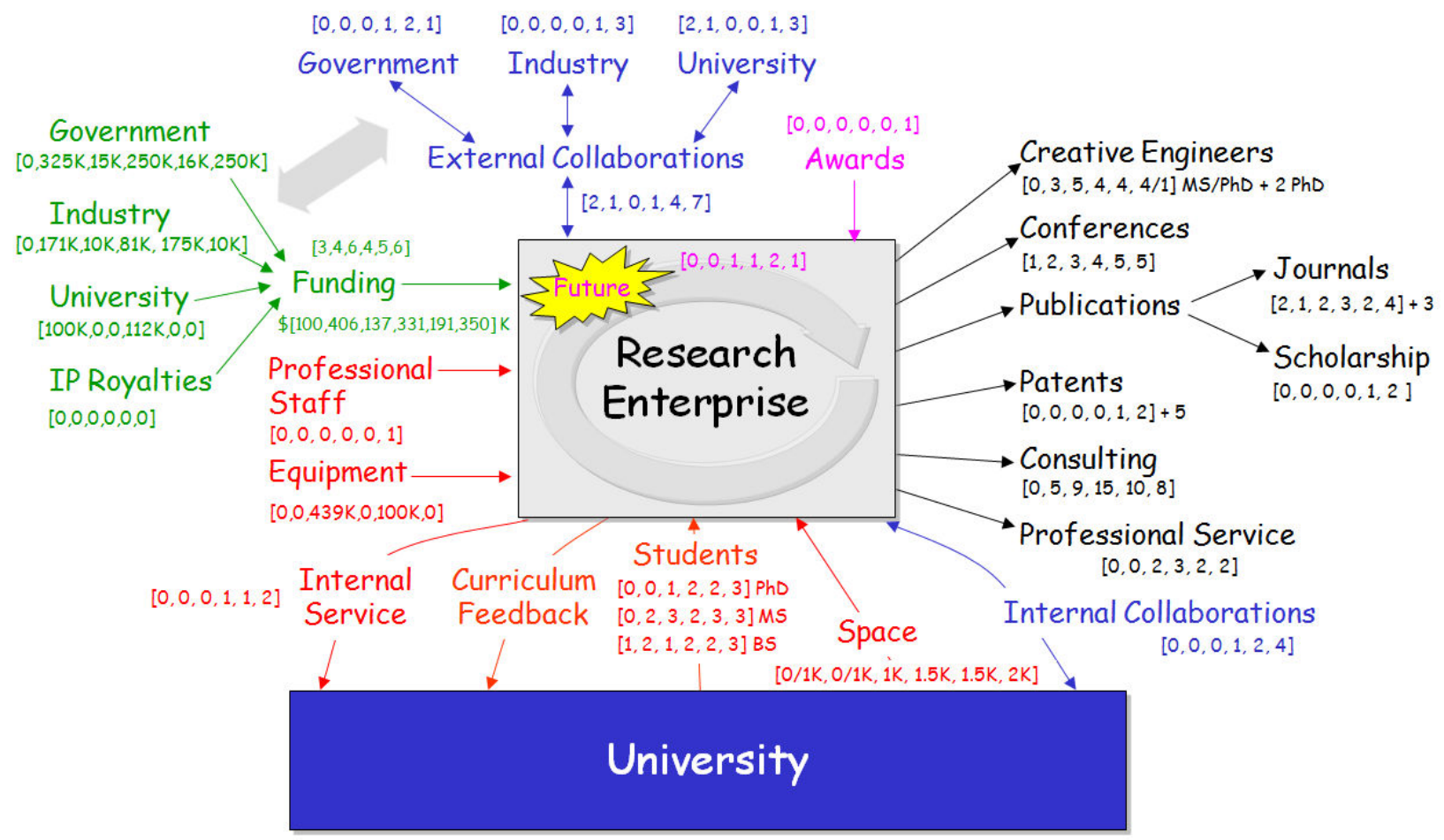

Figure 2. Research entreprenuer model with yearly performance vectors

\section{Tracking Prog ress}

As a faculty member moves towards tenure and promotion it is important to be able to show the mselves and their immediate management that they have a successful research enterprise. One method of showing this process is to establish a time vector that shows quantitative numbers for most of the inputs and outputs shown on the preciously described research entrepreneur model. The time vector should start with the year the faculty member started and end the year they will be put forward for tenure and promotion, e.g. [Starting Year, Year 2, Year 3, Year 4, Year 5, P\&T Year]. It could also be a vector showing the past 5-6 years after the faculty member has 
been tenured and is now moving towards promotion to Full Professor. An example is shown in Figure 2. By looking at these performance vectors, the progress that the faculty member has made over time can be quickly seen. Below will be a discussion of the suggested contents for each of the vectors.

\section{Research Enterprise Products (Shown in Black)}

For these vectors, the numbers should represent what has been produced, not what is waiting to be produced. Although intermediate steps in this process such as submitted papers, book chapters or even patent disclosures are necessary for the enterprise to grow, it is important to focus on real outputs or it will be easy for the faculty member to op timize their enterprise around these almostproducts and never produce anything real.

1. Journals - Refers to refereed journal publications and should only include papers that have been published. In Figure 2, the vector for Journals is given as $[2,1,2,3,2,4]+3$. In this case, year one shows 2 publications, which were most likely the result of the faculty member's dissertation, 1 paper the second year, 2 in the third year, 3 in the fourth year, 2 in the fifth year, and finally 4 pape rs that have been published the sixth year. A successfully operating enterprise should show an increase in publications associated with the core competencies of the enterprise beginning the third or fourth year since the delays for publications can be several years. To show that other papers have been accepted and are waiting for publication, a single number can be added externally to the vector. In this case, there are 3 papers that have been accepted. This shows there has been work do ne, but it has not yet been fully released to the outside world.

2. Scholarship - This vector should include the number of books, book chapters, and monographs that were published in a give n year.

3. Conferences - The number of refereed conference publications. It is recommended that this vector only include refereed conferences and not workshops or presentations at nonprofessional meetings.

4. Patents - This vector should only include issued patents. This restriction implies that most of the patents will show up in the last few years of the probationary period.

5. Consulting - The number of days the faculty member has been contracted to consult each year. Most institutions have a limit on the number of consulting days allowed for a faculty member.

6. Professional Service - This should include a numerical total of the service they are performing for their professional community such as journal editorships, conference chairs, and technical committees. The quality of these activities needs to be evaluated separately.

\section{Building on the University's Infrastructure (Shown in Red)}

The content of the input vectors that build on the uni versity's infrastructure should include: 
1. Students - This vector should only include the number of students actively employed or working within the research enterprise. This can include students on fellowships that are not funded directly by the faculty member. In Figure 2 there are three vectors associated with stude nts; they include one for $\mathrm{PhD}$ stude nts, o ne for MS or ME stude nts, a nd one for BS students.

2. Space - This should include the amount of space in square feet controlled by the faculty member. In some institutions, where most of the laboratory space is shared, the vector should include the effective amount of space used by the faculty member's enterprise. The yearly e ntry could look like individual space/shared space $\}$. As the enterprise grows, so should the total amount of space utilized by the faculty member's enterprise.

3. Internal Service - Should include the number of internal service activities that are assigned to the new faculty member. This could include the departmental committees that the new faculty members have been assigned. This number should be small to guarantee the success of the new faculty member.

\section{Funding the Research Enterprise (Shown in Green)}

Next to the creation and publication of new technologies and services the most important measure of a successful research enterprise is the funding acquired. This funding, listed in the funding vectors, should only include the research expenditures as sociated with the enterprise. Although many of the grants awarded to a faculty member may be very large, nor mally o nly a small percentage of that total funding is used to support the enterprise of the faculty member. There are four main vectors used to describe the funding activities of a faculty member's research program.

1. Government - This vector should include all the money directly spe nt on the research enterprise activities from government grants and contracts (should not include overhead). This can include student and faculty salaries, equipment, space renovation, travel, consumables, etc.

2. Industry - This vector should include all the fund ing that was spent on the enterprise from industrial sources (should not inc lude overhead).

3. University - Includes all the fund ing that was spent on the enterprise from university sources. This can include start- up funding, special university grants, overhead return, and university fellowship and scholarship funding that was awarded to students working in the enterprise.

4. Intellectual Property - This vector should list the revenue obtained for the research enterprise from IP royalties. One of the goals of the research enterprise should be to create new intellectual property that has been patented and licensed by the university. Normally, a percentage of the licensing revenues received by the university on this 
intellectual property will be returned to the faculty member and can be used to build their research program.

5. Funding - There are two vectors associated with this category. The first which is located above the title "funding" is a vector that includes the number of proposals or grants that were submitted by the faculty member. The second, which is located below the title "funding" includes the total research expenditures of the research enterprise.

\section{Extending the Research Enterprise (Shown in Blue)}

The collaborative ties associated with a faculty member will be a key to their success in their professional community and in obtaining grants and contacts.

1. Government - The metrics monitored in this category include the number of people from government agencies that are listed as collaborators in journal and conference publications and proposals. For publications this includes the number of co-authors from government agencies that are listed on published refereed journals and published refereed conference publications. Added to this number for each year are the co-PIs from government agencies that are listed on the awarded contracts and grants.

2. Industry - This includes the number of co-authors from industry listed on published refereed journals, published refereed conference publications, in addition to the number of co-PIs from ind ustry listed on the awarded contracts and grants.

3. External University - This includes the number of co-authors from external universities listed on published refereed journals, published refereed conference publications, in add ition to the number of co-PIs from external universities listed on the awarded contracts and grants.

4. Internal Collaborations - This includes the number of co-author s from the faculty member's university listed on published refereed journal and conference publications, in add ition to the number of co-PIs from the faculty member's university listed on the awarded contracts and grants.

\section{Sustainability (Shown in Magenta)}

The contents of the sustainability vectors include

1. Future - This vector should include the number of proposals and grants that have been submitted in a given year that represent new directions and future capabilities of the enterprise. They should not include proposals or grants that are simple extensions of the current core competencies of the research enterprise.

2. Awards - This should include the number of external awards that were received. These should only include awards from professional societies. 


\section{Discussion}

It is suggested that each year, prior to the faculty member's performance review, this chart should be filled out with the faculty member's accomplishments. If possible, it is best to have an administrative assistant fill out the chart to make sure that the records of the institution match the records of the faculty. This helps reduce the "exaggeration factors" and "surpr ises" that nearly always enter into yearly performance discussions. During the performance review the faculty member and their administrator can review the progress of the research enterprise by exploring the contents of each vector.

For the first year review, most of the vectors will be assigned zeros since the faculty member will not have had the time to get their research engine started. A couple of important vectors to monitor in the first year include journal and conference publications. These should include the published results of the dissertation work done by the faculty member. There should also have been some proposals written and submitted. It is important for the faculty members to understand the importance of obtaining grants and funding for their research. During the second, third, and fourth years the number of zeros in the model should start to reduce. There should start to be contracts and grants awarded, there should be an increase in number of conference papers, journal papers, pa tent disclosures submitted, and professional service and collaborations should start to increase. Also, the number of students involved in the enterprise should start to stabilize in the neighborhood of 10-15. The faculty member should also be adding more graduate students to their program, especially $\mathrm{PhD}$ students if possible. The fifth and sixth years should be highly productive. This is the time when most of the vectors should be filled with numbers greater than zero. This is the time that the research engine should be operating at full potential!

When a faculty member applies for tenure and promotion, o ne of the questions asked by administration is "will this faculty member continue to be productive and move towards promotion to full professor or will they slow down and retire in place after receiving tenure." It is my opinion, that if a faculty member has developed a research enterprise that is continually producing all the academic products that are expected from faculty members, they have demonstrated their ability to fund their enterprise, they are participating in active collaborations with their peers, and they have received the respect of their professional community, then there is a high probability that they will continue to push their enterprise to the next level.

Finally, this model also helps the faculty members understand that a successful research program is not just a collection of journal papers but a process that involves students, collaborators, funding agencies, their professional society, and a lot of hard work.

\section{Conclusions}

This paper has provided the outline of a simple visual model that can be used to monitor the progress and growth of the research enterprise of a faculty member. This tool can be used by a faculty member to understand their progress as well as help them identify the actions they need to take in order to create a successful academic research program. It can also be used by management as a tool to assess the strength and sustainability of a faculty member's research effort. 


\section{Bibliography}

1. John M. Braxton and Marietta Del Favero, "Evaluating scholarship performance: Traditional and emergent assessment templates," New Directions for Institutional Research, Volu me 2002, Nu mber 114, October 1, 2002, pp. 19-32.

2. Halil Dundar and Darrell R. Lewis, "Determinants of research productivity in higher education," Research in Higher Education, Volu me 39, Nu mber 6, December, 1998, pp. 607-631.

3. Peter Seldin, Evaluating Faculty Performance: A Practical Guide to Assessing Teaching, Research, and Service, Wiley, 2006.

4. Raoul A. Arraeola, Developing a Comprehensive Faculty Evaluation System: A Guide to Designing, Building, and Operating Large-Scale Faculty Evaluation Systems, Jossey-Bass, 2006. 